\title{
Doss Porphyria ( $\delta$-Aminolevulinic Acid Dehydratase Porphyria) Presenting with Acute Onset Flaccid Paralysis
}

\author{
Singh $\mathrm{SK}^{1}$, Gauchan $\mathrm{E}^{2}$, Koirala $\mathrm{DP}^{3}$, Rao $\mathrm{KS}^{4}$
}

\begin{abstract}
$\delta$-Aminolevulinic acid dehydratase porphyria is an autosomal recessive disorder of heme synthesis resulting from deficiency of $\delta$-aminolevulinic acid dehydratase (ALAD). Patients present with fatal neurovisceral manifestations and motor neuropathy. Here we report a patient with rapidly progressive flaccid tetraplegia with respiratory and bulbar paralysis. The importance of early diagnosis, prompt treatment and screening of relatives is stressed.
\end{abstract}

Key words: Doss porphyrias, Flaccid tetraplegia, Porphobilinogen, Aminolevulinic acid

\section{Introduction}

$\mathrm{P}$ orphyrias are rare metabolic diseases resulting from altered activities of specific enzymes of the heme biosynthetic pathway. $\delta$-Aminolevulinic acid dehydratase porphyria (ADP), sometimes termed as Doss porphyria results from a deficiency of $\delta$-aminolevulinic acid dehydratase (ALAD) and is inherited as an autosomal recessive trait. Only six cases have been confirmed by mutation analysis. ALAD is the second enzyme in the heme biosynthetic pathway and catalyzes the condensation of 2 molecules of aminolevulinate acid (ALA) to form a monopyrrole, porphobilinogen $(P B G)^{1}$. The prevalence of heterozygous ALAD deficiency was estimated to be $<1 \%$ in Germany and $\approx 2 \%$ in Sweden ${ }^{2}$. Clinical presentation of ADP includes autonomic, central, motor and sensory symptoms. We are reporting a case of a 10 years male with ADP presenting as neurovisceral symptoms.

\section{The Case}

A 10 years male from Western region of Nepal with normal developmental milestones and no prior neuro-visceral symptoms presented with history of severe abdominal pain for five hours duration associated with vomiting and difficulty in breathing. Eight hours later, he developed decreased level of consciousness. There was no history of fever, headache, seizures, and rashes, intake of canned food or drugs. There was no history of consanguinity or similar illness in family members. Patient was intubated at a district hospital because he was not maintaining saturation and then referred to our hospital. On examination, GCS was $8 / 15$, heart rate
'Dr. Sandip Kumar Singh, MBBS, MD Resident, ${ }^{2}$ Dr. Eva Gauchan, MBBS, MD, Assistant Professor, ${ }^{3}$ Dr. Deepak Prasad Koirala, MBBS, MD, Assistant Professor, ${ }^{4}$ Dr. K.S. Rao, MBBS, MD, Professor and HoD. All from the Department of Paediatrics, Manipal Teaching Hospital, Fulbari, Pokhara, Nepal.

\section{Address for correspondence: \\ Dr. Sandip Kumar Singh \\ E-mail: sandeep272@hotmail.com}

\section{How to cite}

Singh SK, Gauchan E, Koirala DP, Rao KS. Doss Porphyria ( $\delta$-Aminolevulinic Acid Dehydratase Porphyria) Presenting with Acute Onset Flaccid Paralysis. J Nepal Paediatr Soc 2015;35(3):280-282.

doi: http://dx.doi.org/10.3126/jnps.v35i3.12509

This work is licensed under a Creative Commons Attribution 3.0 License.

\section{(c) (i)}

was 128 beats/min (reference range 70$110)$, and respiratory rate was 28 breaths/ min, BP: systolic at $70^{\text {th }}$ and diastolic at $50^{\text {th }}$ percentile, $\mathrm{SpO}_{2}: 100 \%$ on T-piece ventilation. CNS examination revealed $4 \mathrm{~mm}$ sluggishly reacting pupils, normal cranial nerves, no signs of meningeal irritation, decreased tone in both limbs with sluggish reflexes and upgoing plantars. Other systemic examination was normal.

Investigation showed WBC: 11,300/ cu.mm with neutrophilic predominance, $\mathrm{Hb}: 13.2 \mathrm{~g} / \mathrm{dl}$, platelet: normal counts, ESR: $50 \mathrm{~mm}$ in $1^{\text {st }}$ hour. Peripheral smear showed normocytic normochromic RBC, C-reactive protein: negative, normal electrolytes, urine, blood sugar, serum amylase and liver function test (LFT). ABG analysis showed respiratory acidosis, Chest X-ray and CT scan head was normal. CSF analysis was not done as patient was haemodynamically unstable. 


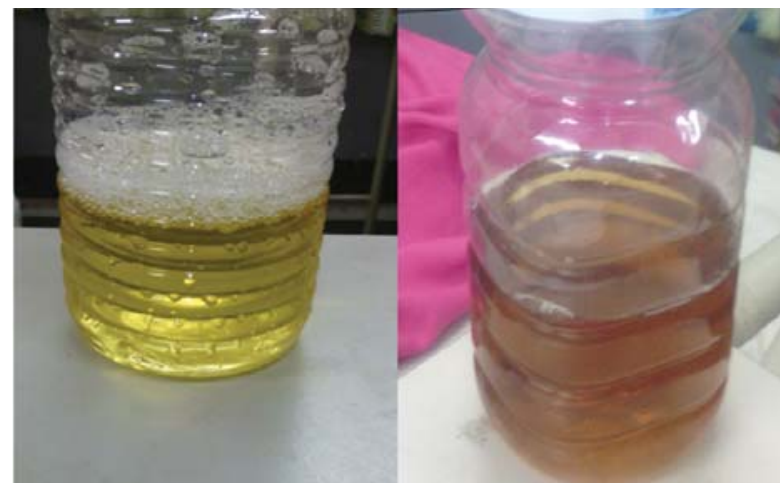

Fig 1: change of urine colour on exposure to sun Before and after exposure to sun Before dextrose therapy ( $5^{\text {th }}$ day)

During hospital stay, no fever or seizure occurred but there was persistent tachycardia and hypotension requiring inotropic support. On $3^{\text {rd }}$ day of illness he was kept on mechanical ventilator due to repeated desaturation. On $4^{\text {th }}$ day there was marked hypotonia with areflexia and equivocal plantars. On $5^{\text {th }}$ day ofillness, colour of urine changed to dark brown on exposure to sunlight (Fig:1). Based on history, examination and urinary findings, a clinical diagnosis of porphyria was made and urine was sent for Porphobilinogen (PBG) and ALA (d-aminolevulinic acid). Urine ALA was 3.18 $\mathrm{mg} / \mathrm{dl}(0.0-0.55 \mathrm{mg} / \mathrm{dl})$; whereas Urine PBG was 0.051 $\mathrm{mg} / \mathrm{dl}(<0.10 \mathrm{mg} / \mathrm{dl})$. Change of colour of urine on exposure to sunlight, increased urine ALA and normal urine PBG suggested a diagnosis of ADP. So 300 grams of $10 \%$ dextrose was started. Erythrocyte ALAD could not be done as child developed persistent bradycardia and expired on $9^{\text {th }}$ day of admission. Erythrocyte ALAD activity and urinary ALA were planned in both parents but could not be done due to financial constraints.

\section{Discussion}

Porphyrias are a group of inherited diseases caused by deficiency of enzymes of the heme synthetic pathway, resulting in accumulation of porphyrins and their precursors. They are classified into hepatic porphyrias with neurological manifestations and erythropoietic porphyrias with no neurological symptoms. ADP, a type of hepatic porphyria is an autosomal recessive condition resulting from deficiency of ALAD. Its prevalence in South East Asia and Nepal is not known; most cases are reported in adolescent males.

ADPpresentswithsevereneurologicmanifestations similar to our case ${ }^{2}$. The typical neuropathy in ADP is an acute or subacute motor axonopathy predominantly

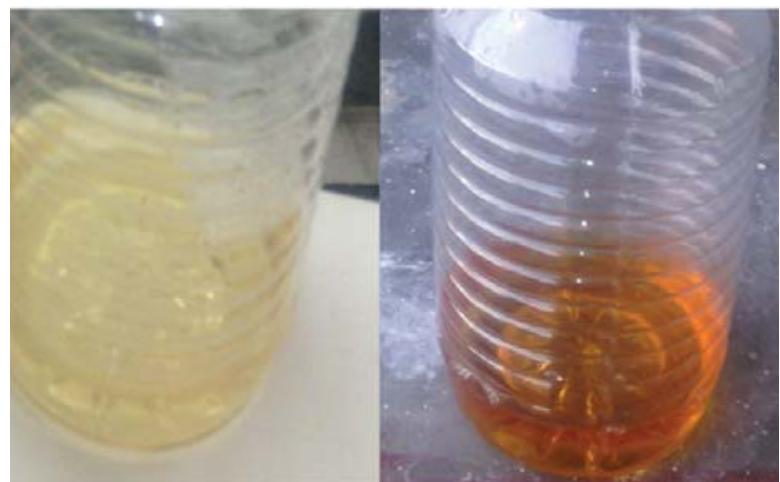

Before and after exposure to sun

After dextrose therapy ( $6^{\text {th }}$ day)

affecting proximal muscles symmetrically and can lead to tetraplegia, with respiratory and bulbar paralysis ${ }^{3}$. Initially, tendon reflexes may be hyperactive and become absent later as in this case. Weakness is usually preceded by episodes of abdominal pain secondary to autonomic neuropathy ${ }^{4}$. Abdominal pain is the most common manifestation occurring in $85-95 \%$ of cases whereas tachycardia is the most common clinical sign ${ }^{5}$. Other symptoms of autonomic dysfunction include hyper or hypotension, diaphoresis and hyponatremia. In this case tetraplagia was preceded by abdominal pain, and during PICU stay persistent tachycardia and hypertension developed, which was followed by bradycardia and hypotension.

Acute Encephalitis as a diagnosis was excluded as there was no fever, convulsions, bizarre movements, or hallucinations, whereas weakness in descending pattern and early bulbar involvement made GuillianBárre syndrome (GBS) less likely.

In our case urinary ALA was raised whereas urinary PBG was normal suggesting the diagnosis. Other causes of increased urine ALA were excluded. Normal LFT excluded acute hepatitis, absence of history of chronic exposure, acute presentation, absence of microcytic hypochromic anaemia excluded lead poisoning, however zinc protoporphyrin was not done for definitive diagnosis. Late presentation, normal odour and absence of hepatic and renal involvement excluded tyrosinemia type-I.

Confirmation of diagnosis can be done by erythrocyte ALAD which was not possible in our case as child died before the investigation could be done. Normal Urinary ALA of both parents along with halfnormal activity of erythrocyte ALAD would have established the diagnosis but it was not possible due to financial constraints. 
Management is symptomatic along with dextrose and hemin. Carbohydrate acts by down-regulation of heme synthesis whereas hemin replenishes the depleted heme pool and provides negative feedback on heme synthesis ${ }^{5}$. However hemin was not available in our part of the world. As this is an autosomal recessive disorder, genetic counselling could have been done and screening should be advised for other siblings as well.

\section{Conclusion}

Acute Porphyria should always be suspected in patients with gastrointestinal symptoms and neuropsychiatric manifestations. Families of these individuals should be subjected to suitable enzyme tests, to screen asymptomatic relatives.

Acknowledgment: The authors are deeply indebted to the patient party for allowing them to present his information as a case report. we thank $\mathrm{Dr}$ Sudhir Adhikari, Dr Rajnees Mishra, Dr Laxmi KC and Dr Isha Bhandari for the support.

\section{Reference}

1. Sassa S. $\delta$-aminolevulinic acid dehydratase assay. Enzyme 1982;28:133-45.

2. Anderson KE, Lee C, Desnick RJ. The porphyrias. In: Kliegman RM, Behrman RE, Stanton BF, Schor NF eds. Nelson Textbook of Pediatrics. $19^{\text {th }}$ edition vol.1 New Delhi: Elsevier; 2011. pp. 517.

3. Albers JW, Fink JK. Porphyric neuropathy. Muscle Nerve 2004;30(4):410-22.

4. Kauppinen R, Mustajoki P. Prognosis of acute porphyria: occurrence of acute attacks, precipitating factors, and associated diseases. Medicine (Baltimore) 1992;71:1-13.

5. Anderson KE, Bloomer JR, Bonkovsky $\mathrm{HL}$, Kushner JP, Pierach CA, Pimstone NR and Desnick RJ. Recommendations for the Diagnosis and Treatment of the Acute Porphyrias. Ann Intern Med 2005;142:439-50. 